\title{
Indicativos de situações didáticas na Base Nacional Comum Curricular: fomentando
}

\section{o protagonismo do aluno}

\author{
Didactic situations in the Common National Curriculum Base: fostering the students' protagonism \\ Indicativos de situaciones didácticas en la Base Nacional Común Curricular: fomentando el
}

protagonismo del alumno

Recebido: 15/11/2021 | Revisado: 21/11/2021 | Aceito: 24/11/2021 | Publicado: 07/12/2021

\author{
Maria Eduarda Maquiné da Silva \\ ORCID: https://orcid.org/0000-0002-5480-9556 \\ Universidade Federal do Amazonas, Brasil \\ E-mail: maquine.ufam@gmail.com \\ Jean Michel dos Santos Menezes \\ ORCID: https://orcid.org/0000-0003-2769-1887 \\ Universidade Federal do Amazonas, Brasil \\ E-mail: jeanmichelsm@ufam.edu.br \\ Sidilene Aquino de Farias \\ ORCID: https://orcid.org/0000-0003-3866-207X \\ Universidade Federal do Amazonas, Brasil \\ E-mail: sfarias@ufam.edu.br
}

\begin{abstract}
Resumo
Nesta pesquisa objetivou-se identificar na Base Nacional Comum Curricular indicativos de situações didáticas que favoreçam o protagonismo do estudante. As situações didáticas possibilitam que o professor prepare o aluno para enfrentar as demandas sociais, assim como, podem conduzir este aluno ao aprender a conhecer, aprender a fazer, aprender a conviver e aprender a ser. Para tanto, adotou-se pesquisa com caráter qualitativo, utilizando-se um protocolo de análise documental organizado a partir de dois temas: (1) competências e habilidades e, (2) situações didáticas como princípio curricular. A partir disso, buscou-se identificar trechos que apontassem para potenciais experiências que possibilitem desenvolver o protagonismo estudante no processo de ensino e aprendizagem por meio das seguintes palavras-chave: estratégia, atividade, protagonismo, situações-problema, metodologia, autorreflexão, metacognição, autoavaliação e reflexão. Os dados obtidos foram analisados utilizando-se a técnica Análise de Conteúdo. Os resultados mostram que há preocupação em utilizar diversas estratégias e recursos didáticos que favoreçam o protagonismo estudante, como o uso de Tecnologias de Informação e Comunicação, métodos investigativos e métodos de resolução de problemas. Dessa maneira, possibilita o professor criar situações didáticas que proporcione a aprendizagem ativa estudante, bem como, uma formação de um aluno crítica e consciente. o resumo.
\end{abstract}

Palavras-chave: Situações didáticas; BNCC; Analise documental.

\begin{abstract}
This research aimed to identify in the Common National Curriculum Base (BNCC, in the Portuguese acronym) indications of didactic situations that foster students' protagonism. Didactic situations allow teachers to prepare students to face social demands as well as help students learn to know, learn to do, learn to interact, learn to become citizens and, learn to be protagonists of their learning. To this end, the study supported by a qualitative approach used a protocol for the document analysis organized according to the following themes: competences and skills and, didactic situations as a curricular principle. Based on this, the research aimed to identify excerpts that indicated potential experiences that allow students to become protagonists of their learning process. These keywords guided the analysis: strategy, activity, protagonism, problem situations, methodology, self-reflection, metacognition, selfevaluation and reflection. The data generated was analyzed according to Content Analysis technique. The results demonstrate there is a concern for using various strategies and teaching resources that stimulate students to act as protagonists, as well as the use of Communication and Information Technologies, research and problem solving methods. Thus, allowing teachers to create didactic situations that provide students' active learning and the education of critical and aware students.
\end{abstract}

Keywords: Didactic situations; $B N C C$; Document analysis. 


\begin{abstract}
Resumen
Esta pesquisa tuvo como objetivo identificar en la Base Nacional Común Curricular (BNCC, el acrónimo en portugués) indicativos de situaciones didácticas que favorezcan el protagonismo del estudiante. Las situaciones didácticas posibilitan que el profesor prepare el alumno para afrontar las demandas sociales. Para eso, se adoptó una pesquisa cualitativa, utilizando un protocolo de análisis documental organizado a partir de dos temas: (1) competencias y habilidades y, (2) situaciones didácticas como principio curricular. A partir de eso, se buscó identificar pasajes que apuntasen experiencias potenciales que posibiliten desarrollar el protagonismo del estudiante en el proceso de enseñanza y aprendizaje por medio de las siguientes palabras clave: estrategia, actividad, protagonismo, situaciones-problema, metodología, auto reflejo, metacognición, auto evaluación y reflejo. Los datos obtenidos fueran analizados utilizándose la técnica Análisis del Contenido. Los resultados muestran que hay una preocupación en utilizar diversas estrategias y recursos didácticos que favorezcan el protagonismo del estudiante, como el uso de las Tecnologías de Información y Comunicación, métodos investigativos y métodos de resolución de problema. De esa manera, posibilita el profesor a crear situaciones didácticas que proporcione el aprendizaje de forma activa del estudiante, así como la formación de un alumno crítico y consciente.
\end{abstract}

Palabras clave: Situaciones didácticas; BNCC, Análisis documental.

\title{
1. Introdução
}

Em um mundo globalizado é de extrema importância que a sociedade saiba se posicionar frente aos desafios impostos ao longo de sua convivência com outros seres e, para que isso aconteça, é fundamental que o jovem, em sua caminhada escolar, desenvolva um conjunto de aprendizagens essenciais (Vilanova, 2015).

Dessa forma, durante a Comissão Internacional sobre Educação para o Século XXI destacou a importância da educação no desenvolvimento contínuo, considerando-a como uma via que conduz o desenvolvimento humano mais harmonioso, mais autêntico. A comissão expressa ainda a necessidade de uma aquisição de saberes de forma eficaz, mas sem que as pessoas fiquem submergidas em um mar de informações efêmeras (Delors et al., 1998).

A eminente demanda desses novos conhecimentos, saberes e habilidades exigidas da prática educativa para formação e desenvolvimento humano, aponta a relevância do "como ensinar" e "porque ensinar", atentando-se às mudanças ocorridas no decorrer da história. Com isso, podemos considerar que os objetos de aprendizagem tendem a sofrer mudanças com o passar do tempo (Pozo, 2002).

Nessa perspectiva, a resolução CNE/CP No 2/2019 expressa que o docente deve planejar ações didáticas que resultem em aprendizagens efetivas adotando um repertorio diversificado de estratégias didático-pedagógicas, considerando principalmente o meio em que os estudantes vivem (Brasil, 2019). Esses conjuntos de condições no processo de ensino e aprendizagem são as denominadas Situações Didáticas (Brousseau, 2008).

\subsection{Situações Didáticas e o Protagonismo do Estudante}

Segundo Roegiers (2006), no contexto escolar, o termo situação aponta para acontecimentos no âmbito da sala de aula, ou seja, designa interações entre professor e alunos, tendo como fim a aprendizagem. Isto implica em intenção didática, pois o professor a partir de determinadas escolhas (tarefas, recursos) medeia a relação entre aluno e conhecimento.

Brousseau (2008) acentua que uma situação pode ocorrer em quatro etapas, porém estas podem não ocorrer de maneira linear, sendo: (1) situação-suporte; (2) situação como ferramenta pedagógica - professor e intenção pedagógica; (3) situação-contrato - aluno e contrato didático e; (4) situação-ação (Quadro 1). 
Quadro 1 - Características das situações didáticas.

\begin{tabular}{|c|l|}
\hline Situações & \multicolumn{1}{c|}{ Características } \\
\hline Situação-suporte & $\begin{array}{l}\text { Consiste em situações didáticas e adidáticas com a finalidade de instigar o aluno, de } \\
\text { modo que possa perceber e refletir, assim como evoluir. }\end{array}$ \\
\hline Situação como ferramenta pedagógica & $\begin{array}{l}\text { O meio é o determinante nessa situação, pois a partir deste é possível realizar tomadas } \\
\text { de decisões segundo as regras, estratégias e conhecimentos. }\end{array}$ \\
\hline Situação-contrato & $\begin{array}{l}\text { Refere-se às condições que determinam o compromisso de cada participante da situação } \\
\text { e, que possibilite, futuramente a prestação de contas entre os envolvidos. }\end{array}$ \\
\hline Situação-ação & $\begin{array}{l}\text { É dado pela situação em que os alunos passam a aprender por meio de métodos de } \\
\text { resolução de problemas. }\end{array}$ \\
\hline
\end{tabular}

Fonte: Adaptado de Brousseau (2008)

Nessas etapas, os estudantes manifestam reações que apontam características das situações às quais foram submetidos e, com isso podem desenvolver habilidades referentes à análise, ao levantamento de hipóteses, ao debate em grupo, ao desenrolar de estratégias, a argumentação e a tomada de decisões, características estas concernentes ao método de resolução de problemas (Brousseau, 2008). Diante disso, o aluno passa a ter um papel de destaque na execução de situações as quais foi submetido, tornando-o protagonista do seu processo de aprendizagem, visto que o termo protagonismo é definido como a pessoa que se destaca em qualquer situação atuando no papel mais importante (Protagonismo, 2021).

Volkweiss et al (2019) encaram o protagonismo como elemento fundamental para a construção do conhecimento durante a formação dos estudantes, respeitando aspectos que promovam o desenvolvimento de sua autonomia, uma vez que estudantes autônomos são àqueles capazes de pensar, agir, transformar e decidir de forma crítica. Sendo assim, deve-se respeitar a autonomia desse aluno, sua linguagem, sua inquietude e sua curiosidade uma vez que tais fatores são essenciais na construção do conhecimento (Freire, 2019).

A escolha de Situações Didáticas com determinadas características, como situações problema, pode contribuir no protagonismo do estudante no processo de ensino e aprendizagem nas aulas de Ciências/Química dado que essas escolhas podem acarretar o desenvolvimento de habilidades supramencionadas que promovam o protagonismo estudante. Diante do exposto, o presente estudo tem por objetivo identificar indícios de situações didáticas na Base Nacional Comum Curricular (BNCC) que indiquem possibilidades para elaboração de situações didáticas que favoreçam o protagonismo estudantil.

\section{Metodologia}

A pesquisa apresenta características da abordagem qualitativa, pois explora contextos que não podem ser facilmente descritos numericamente (Moreira \& Caleffe, 2008), visto que na pesquisa em Ensino faz-se uso de métodos e técnicas que possibilitem a obtenção de dados descritivos (Bogdan \& Biklen, 2013). Assim, na obtenção dos dados foi utilizada a Análise Documental como estratégia de levantamento de dados, que tem como fonte de dados tabelas, estatísticas, jornais, revistas, relatórios, documentos oficiais, cartas, entre outros (Lüdke \& André, 2013).

Inicialmente, foi realizada uma leitura prévia da BNCC, em especial, da seção "A Etapa do Ensino Médio" e a "Área de Ciências da Natureza e suas Tecnologias", tendo em vista a elaboração de um protocolo de análise documental (Quadro 2), que foi organizado com as seguintes temáticas: (1) competências e habilidades e, (2) situações didáticas como princípio curricular; visando levantar indícios que apontem as situações didáticas que favoreçam o protagonismo dos estudantes no Ensino Médio.

A partir disso, foi realizada uma busca por termos como: estratégia, atividade, protagonismo, situações-problema, metodologia autorreflexão, metacognição. autoavaliação, reflexão; buscando trechos que apontassem para experiências que devem ser vivenciadas pelos estudantes que possibilitem sua formação ampla numa perspectiva de protagonizar suas aprendizagens. 
Quadro 2 - Protocolo de análise documental.

\begin{tabular}{|c|l|}
\hline Documento analisado & Base Nacional Comum Curricular (2018) \\
\hline Questão de estudo & $\begin{array}{l}\text { Como são contempladas as situações didáticas a serem utilizadas pelos professores da educação básica no } \\
\text { documento oficial? }\end{array}$ \\
\hline Objetivo & $\begin{array}{l}\text { Identificar indícios de situações didáticas a serem utilizadas pelos professores da educação básica no } \\
\text { documento oficial. }\end{array}$ \\
\hline Palavras-chave & $\begin{array}{l}\text { Estratégia, atividade, protagonismo, situações-problema, metodologia, autorreflexão, metacognição. } \\
\text { autoavaliação, reflexão. }\end{array}$ \\
\hline O que observar? & $\begin{array}{l}\text { A pesquisa foi realizada em todo o documento, buscando relações com as palavras-chave, dependendo da } \\
\text { categoria. Será dada uma atenção as sessões nos documentos que tragam "A Etapa do Ensino Médio" e a } \\
\text { "Área de Ciências da Natureza e suas Tecnologias" bem como as competências e habilidades. }\end{array}$ \\
\hline
\end{tabular}

Fonte: Autores (2021).

Os dados obtidos foram analisados utilizando-se a Análise de Conteúdo (AC), sendo elaboradas duas temáticas: competências e habilidades; situações didáticas como princípio curricular (Quadro 3). Nesta abordagem, a AC apresentou parte da sua construção ao longo do processo e, posteriormente, os objetivos foram moldando-se e delineando à medida que a investigação avançou. Dessa forma, o interesse não está na descrição dos conteúdos, e sim no que poderão produzir após serem tratados (Bardin, 2009). Assim, a descrição torna-se a primeira etapa, seguida da inferência e terminando na interpretação.

Quadro 3 - Temas de análise.

\begin{tabular}{|c|l|}
\hline Tema & \multicolumn{1}{c|}{ Descrição } \\
\hline Competências e habilidades & $\begin{array}{l}\text { Como as situações didáticas fazem presente nas competências e habilidades que o estudante deve } \\
\text { desenvolver no processo educativo? }\end{array}$ \\
\hline $\begin{array}{c}\text { Situações didáticas como } \\
\text { princípio curricular }\end{array}$ & $\begin{array}{l}\text { Como as situações didáticas são tratadas nesses documentos? Quais características dessas situações } \\
\text { são citadas? Qual importância é dada às situações no texto desse documento? }\end{array}$ \\
\hline
\end{tabular}

Fonte: Autores (2021).

\section{Resultados e Discussão}

A seguir são apresentados os dados obtidos por meio da análise temática. A primeira temática, Competências $e$ Habilidades, tem a finalidade de analisar como as situações didáticas configuram nas competências e habilidades a serem desenvolvidas pelos alunos durante a Educação Básica. A segunda temática Situações Didáticas como Princípio Curricular, tem por intuito abordar os indícios de situações didáticas encontrados no documento, bem como, suas características considerando como um princípio curricular. Pois, o documento apresenta, entre outros aspectos, significados no que concernem o processo de ensino e aprendizagem, bem como assegurar aprendizagens essenciais para os estudantes.

No decorrer da leitura prévia e posterior análise do documento, pode-se observar que as situações didáticas não são citadas de maneira direta no documento, mas sim elementos que as constituem, sendo estes essenciais para auxiliar o professor na preparação de suas aulas, tendo em vista a especificidade de seus contextos. Logo, os temas foram construídos partir desses elementos que integram as situações didáticas.

\subsection{Tema: Competências e Habilidades}

O documento caracteriza competência como a mobilização de conhecimentos, habilidades, atitudes e valores para resolver demandas complexas da vida cotidiana, enfatizando que as habilidades são expressas pela garantia de determinadas aprendizagens por parte do aluno ao longo de sua construção do conhecimento. 
As habilidades expressam as aprendizagens essenciais que devem ser asseguradas aos alunos nos diferentes contextos escolares. Para tanto, elas são descritas de acordo com uma determinada estrutura. (BNCC, 2018, p. 29)

Para mobilização destas habilidades em determinados contextos é necessário proporcionar a esse processo educativo situações didáticas coerentes com as habilidades a serem desenvolvidas. Logo, o professor precisa planejar tais situações de modo que possibilite fatores como argumentação, reflexão, investigação e tomada de decisões. Portanto, as situações didáticas não podem ser centradas no professor, mas sim com o intuito de proporcionar ao aluno um papel ativo no momento de sua aprendizagem, sendo este o protagonista dessas situações (Freire, 2019; Wolkweiss, 2019).

Brousseau (2008), a partir da ideia de situações-ação que utilizam a metodologia de resolução de problemas e de situações-suporte, descreve a promoção de habilidades investigativas dos alunos no decorrer das referidas situações didáticas, além de expressar que mediante estas o aluno passa a ser "atuante" no processo de ensino e aprendizagem. Logo, por se tratar de componentes que o aluno poderá desenvolver durante sua formação, as situações didáticas se fazem presente por meio de características presentes nas Competências Gerais (Quadro 4), Competências Específicas e Habilidades que fomentem o protagonismo e o elementos do ensino por investigação desenvolvidos a partir da execução de situações-ação e situaçõessuporte. 
Quadro 4 - Características das situações didáticas nas competências gerais da BNCC.

\begin{tabular}{|l|}
\hline \multicolumn{2}{|c|}{ Competências gerais } \\
\hline Valorizar e utilizar os conhecimentos historicamente construídos \\
sobre o mundo físico, social, cultural e digital para entender e \\
explicar a realidade, continuar aprendendo e colaborar para a \\
construção de uma sociedade justa, democrática e inclusiva \\
(BNCC, 2018, p. 9).
\end{tabular}

Exercitar a curiosidade intelectual e recorrer à abordagem própria das ciências, incluindo a investigação, a reflexão, a análise crítica, a imaginação e a criatividade, para investigar causas, elaborar e testar hipóteses, formular e resolver problemas e criar soluções (inclusive tecnológicas) com base nos conhecimentos das diferentes áreas (BNCC, 2018, p. 9).

Utilizar diferentes linguagens - verbal (oral ou visual-motora, como Libras, e escrita), corporal, visual, sonora e digital -, bem como conhecimentos das linguagens artística, matemática $e$ científica, para se expressar e partilhar informações, experiências, ideias e sentimentos em diferentes contextos e produzir sentidos que levem ao entendimento mútuo (BNCC, 2018, p. 9).

Compreender, utilizar e criar tecnologias digitais de informação $e$ comunicação de forma crítica, significativa, reflexiva e ética nas diversas práticas sociais (incluindo as escolares) para se comunicar, acessar e disseminar informações, produzir conhecimentos, resolver problemas e exercer protagonismo e autoria na vida pessoal e coletiva (BNCC, 2018, p. 9).

Valorizar a diversidade de saberes e vivências culturais e apropriar-se de conhecimentos e experiências que lhe possibilitem entender as relações próprias do mundo do trabalho e fazer escolhas alinhadas ao exercício da cidadania e ao seu projeto de vida, com liberdade, autonomia, consciência crítica e responsabilidade (BNCC, 2018, p. 9).

Argumentar com base em fatos, dados e informações confiáveis, para formular, negociar e defender ideias, pontos de vista $e$ decisões comuns que respeitem e promovam os direitos humanos, a consciência socioambiental e o consumo responsável em âmbito local, regional e global, com posicionamento ético em relação ao cuidado de si mesmo, dos outros e do planeta (BNCC, 2018, p. 9).

Exercitar a empatia, o diálogo, a resolução de conflitos $e$ a cooperação, fazendo-se respeitar e promovendo o respeito ao outro e aos direitos humanos, com acolhimento e valorização da diversidade de indivíduos e de grupos sociais, seus saberes, identidades, culturas e potencialidades, sem preconceitos de qualquer natureza (BNCC, 2018, p. 10).

Agir pessoal e coletivamente com autonomia, responsabilidade, flexibilidade, resiliência e determinação, tomando decisões com base em princípios éticos, democráticos, inclusivos, sustentáveis e solidários (BNCC, 2018, p. 10)..

\section{das situaçoes didáticas}

Mediante a utilização de sequências didáticas especificas para o desenvolvimento de competências, o aluno passar a empregar os conhecimentos adquiridos fora do contexto escolar e sem indicação intencional. Brousseau (2008) denomina tal característica como uma situação adidática, pertencente às situações-suporte.

Com o uso de estratégias e metodologias de ensino de caráter investigativo, os alunos são instigados a desenvolver características como reflexão, debates, tomada de decisões, pensamento crítico e formulação de hipóteses, aspectos esses observados ao longo da execução de situações-ação (Broussau, 2008), podendo futuramente ser aplicado em situações adidáticas do cotidiano deste aluno.

Devido à inabilidade do aluno frente às situações adidáticas, o professor é o responsável por promover situações as quais os alunos possam solucionar. Estas ao serem empregadas em um contexto educacional em que o aluno interage com o meio tornamse uma situação didática.

A partir da manipulação de determinadas situações-suporte podese proporcionar o protagonismo do estudante no que concerne a construção de seu conhecimento, bem como desenvolver tais competências especificas que os ajude a lidar com as demandas de seu cotidiano (Brosseau, 2008).

Ao dispor de situações atribuindo-as um caráter pedagógico e considerando a heterogeneidade do aluno, o professor estabelece contratos de ensino em que cada parte envolvida - podendo ser professor e aluno - teoriza o que podem esperar do outro.

No caso do professor, há possibilidade, a partir desse contrato, de realizar determinadas intervenções (Brousseau, 2008). Sendo estas realizadas por sucessivas situações didáticas com elementos adidáticos ou até mesmo por meio da execução de situações-ação fazendo com que o aluno desenvolva valores e atitudes ao longo do processo de ensino e aprendizagem bem como as características das competências destacadas.

A reflexão acerca de temas empregados nas situações didáticas e posterior tomadas de decisão são elementos essenciais construídos no decorrer do processo uma vez que esse aluno se converte em protagonista não somente em seu ambiente de aprendizagem como também nas futuras relações sociais foras do contexto escolar (Freire, 2019; Wolkweiss, 2019). A flexibilização das situações observadas em diversos momentos da aprendizagem (Brousseau, 2008) possibilitam o desenvolvimento de aspectos essenciais para o ambiente escolar como também para o contexto ao qual o aluno se insere, ou seja, com base na dinâmica realizada a partir das situações didáticas o aluno desenvolve competências no que concerne a resolução de possíveis situações adidáticas impostas em seu cotidiano.

Fonte: Autores (2021).

Considerando que a escolha de uma situação didática resulta na promoção de competências e habilidades específicas para os estudantes, o professor é incumbido de selecionar os instrumentos mais adequados com o intuito de fornecer situações das quais os alunos passem a se perceber durante o processo de ensino e aprendizagem de modo que estes vivenciem ativamente a construção de seu conhecimento. Para Volkweiss et al (2019), ao propor um ambiente de aprendizagem acolhedor o docente estabelece vínculos e provoca no aluno o sentimento de aptidão e, capacidade de se tornar um participante ativo de sua aprendizagem. 
Santos, Souza e Fontes (2020) apontam a atuação da escola ao dispor atividades pedagógicas que proporcionam resultados significativos em que os alunos são protagonistas do saber e não meros receptores do conhecimento. Com isso, as situações didáticas exemplificadas por Brousseau (2008) direcionam o professor a refletir sobre a situação mais adequada a se manusear uma vez que esta, ao ser empregada com finalidade didática, possibilita a promoção da construção do conhecimento de forma protagônica bem como das competências e habilidades supramencionadas de modo que o estudante saiba solucionar situações adidáticas pertencentes ao contexto aos quais os alunos são inseridos em sua vida.

Em relação à área Ciências da Natureza e suas Tecnologias (CNT), o desenvolvimento das Competências Específicas é responsabilidade dos três componentes curriculares, Biologia, Física e Química, devendo ser contemplado nas três séries do Ensino Médio, sendo que a partir dessas competências são expressas as habilidades que os estudantes devem alcançar em cada etapa do seu processo de aprendizagem. A primeira competência específica da área CNT diz respeito à análise dos fenômenos naturais e processos tecnológicos de modo que o aluno possa refletir e propor soluções que minimizem os impactos socioambientais e melhore sua condição de vida no mundo.

Analisar fenômenos naturais e processos tecnológicos, com base nas interações e relações entre matéria e energia, para propor ações individuais e coletivas que aperfeiçoem processos produtivos, minimizem impactos socioambientais e melhorem as condições de vida em âmbito local, regional e global (BNCC, 2018, p. 554).

As características, das situações didáticas que podem ser interpretadas a partir do conjunto de habilidades (Quadro 5) pertencentes a competência supracitada, podem ser desenvolvidas por meio das situações conceituadas por Brousseau (2008).

Quadro 5 - Características das situações didáticas relacionadas ao conjunto de habilidades pertencentes à Competência Específica 1 da área CNT.

\begin{tabular}{|c|c|}
\hline $\begin{array}{l}\text { Habilidades } \\
\end{array}$ & Características das situações didáticas \\
\hline $\begin{array}{l}\text { Analisar e representar, com ou sem o uso de dispositivos e de } \\
\text { aplicativos digitais específicos, as transformações e conservações } \\
\text { em sistemas que envolvam quantidade de matéria, de energia e de } \\
\text { movimento para realizar previsões sobre seus comportamentos em } \\
\text { situações cotidianas e em processos produtivos que priorizem o } \\
\text { desenvolvimento sustentável, o uso consciente dos recursos naturais } \\
\text { e a preservação da vida em todas as suas formas (BNCC, 2018, p. } \\
\text { 555). }\end{array}$ & \multirow{2}{*}{$\begin{array}{l}\text { Com o uso de determinadas situações didáticas de caráter } \\
\text { investigativo, os alunos são estimulados a pensar, levantar } \\
\text { hipóteses, discutir suas ideias e tomar decisões de forma crítica } \\
\text { (Zômpero e Laburú, 2011; Lima, 2012; Texeira et al, 2015). } \\
\text { Características estas essenciais na utilização de situações-ação bem } \\
\text { como nas situações como ferramenta pedagógica. }\end{array}$} \\
\hline $\begin{array}{l}\text { Realizar previsões, avaliar intervenções elou construir protótipos } \\
\text { de sistemas térmicos que visem à sustentabilidade, considerando } \\
\text { sua composição e os efeitos das variáveis termodinâmicas sobre seu } \\
\text { funcionamento, considerando também o uso de tecnologias digitais } \\
\text { que auxiliem no cálculo de estimativas e no apoio à construção dos } \\
\text { protótipos (BNCC, } 2018, \text { p. } 555) \text {. }\end{array}$ & \\
\hline $\begin{array}{l}\text { Utilizar o conhecimento sobre as radiações e suas origens para } \\
\text { avaliar as potencialidades e os riscos de sua aplicação em } \\
\text { equipamentos de uso cotidiano, na saúde, no ambiente, na indústria, } \\
\text { na agricultura e na geração de energia elétrica (BNCC, 2018, p. } \\
555 \text { ). }\end{array}$ & \multirow{3}{*}{$\begin{array}{l}\text { Brousseau (2008) apresenta as situações adidáticas como àquela } \\
\text { onde os alunos utilizam os conhecimentos adquiridos no ambiente } \\
\text { de aprendizagem em seu contexto social de forma não intencional. } \\
\text { Sendo assim, as características das situações didáticas são } \\
\text { perceptíveis em tais habilidades específicas do documento no que } \\
\text { concerne o emprego destas características em seu contexto. }\end{array}$} \\
\hline $\begin{array}{l}\text { Avaliar os benefícios e os riscos à saúde e ao ambiente, } \\
\text { considerando a composição, a toxicidade e a reatividade de } \\
\text { diferentes materiais e produtos, como também o nível de exposiçãão } \\
\text { a eles, posicionando-se criticamente e propondo soluções } \\
\text { individuais elou coletivas para seus usos e descartes responsáveis } \\
\text { (BNCC, 2018, p. 555). }\end{array}$ & \\
\hline $\begin{array}{l}\text { Analisar os ciclos biogeoquímicos e interpretar os efeitos de } \\
\text { fenômenos naturais e da interferência humana sobre esses ciclos, } \\
\text { para promover ações individuais e/ ou coletivas que minimizem } \\
\text { consequências nocivas à vida (BNCC, 2018, p. 555). }\end{array}$ & \\
\hline $\begin{array}{l}\text { Avaliar, com ou sem o uso de dispositivos e aplicativos digitais, } \\
\text { tecnologias e possíveis soluções para as demandas que envolvem a } \\
\text { geração, o transporte, a distribuição e o consumo de energia }\end{array}$ & $\begin{array}{l}\text { O docente, ao fazer uso das Tecnologias de Informação e } \\
\text { Comunicação (TICs) com viés didático proporciona os alunos } \\
\text { habilidades tecnológicas assim como os estimulam a mudanças }\end{array}$ \\
\hline
\end{tabular}


elétrica, considerando a disponibilidade de recursos, a eficiência energética, a relação custo/benefício, as características geográficas e ambientais, a produção de resíduos e os impactos socioambientais e culturais (BNCC, 2018, p. 555).

Realizar previsões qualitativas e quantitativas sobre o funcionamento de geradores, motores elétricos e seus componentes, bobinas, transformadores, pilhas, baterias e dispositivos eletrônicos, com base na análise dos processos de transformação e condução de energia envolvidos - com ou sem o uso de dispositivos e aplicativos digitais -, para propor ações que visem a sustentabilidade (BNCC, 2018, p. 555). comportamentais, podendo colocar esse aluno em um papel ativo durante o processo de aprendizagem (Dionízio et al., 2019). A maneira como esta será utilizada no ambiente de aprendizagem fica então a cargo do docente durante a situação que executará levando em consideração a especificidade de cada turma.

Fonte: Autores (2021).

Para proporcionar o desenvolvimento das habilidades específicas supramencionadas, as TICs empregadas no ambiente de aprendizagem devem ter finalidade didática, ou seja, o professor é o responsável por refletir e organizar qual melhor TIC a ser utilizada de modo que esta assessore a efetividade da execução da situação didática escolhida pelo docente (Silva \& Soares, 2018; Dionízio et al., 2019).

A segunda competência específica corresponde à interpretação sobre a vida para realização de previsões e tomadas de decisões éticas e responsáveis.

Analisar e utilizar interpretações sobre a dinâmica da Vida, da Terra e do Cosmos para elaborar argumentos, realizar previsões sobre o funcionamento e a evolução dos seres vivos e do Universo, e fundamentar e defender decisões éticas e responsáveis (BNCC, 2018, p. 556).

As características das situações didáticas que podem ser inferidas a partir do conjunto de habilidades (Quadro 6) concernentes a segunda Competência Específica podem ser desenvolvidas por meio das seguintes situações didáticas estruturadas a partir do ensino por investigação (Brousseau, 2008).

Quadro 6 - Características das situações didáticas relacionadas as habilidades pertencentes à Competência Específica 2.

\begin{tabular}{|c|c|}
\hline Habilidades & Características das situações didáticas \\
\hline $\begin{array}{l}\text { Analisar e discutir modelos, teorias e leis propostos em diferentes } \\
\text { épocas e culturas para comparar distintas explicações sobre o } \\
\text { surgimento e a evolução da Vida, da Terra e do Universo com as } \\
\text { teorias científicas aceitas atualmente (BNCC, 2018, p. 557). }\end{array}$ & \multirow{3}{*}{$\begin{array}{l}\text { As características das situações didáticas se fazem presente nas } \\
\text { habilidades por meio da aplicação de situações-ação com } \\
\text { metodologias de resolução de problemas. Estas, além de } \\
\text { proporcionar o protagonismo estudantil durante a construção do } \\
\text { conhecimento, impulsionam também aspectos relacionados ao } \\
\text { método investigativo (Brousseau, 2008). }\end{array}$} \\
\hline $\begin{array}{l}\text { Elaborar explicações, previsões e cálculos a respeito dos } \\
\text { movimentos de objetos na Terra, no Sistema Solar e no Universo } \\
\text { com base na análise das interações gravitacionais, com ou sem o } \\
\text { uso de dispositivos e aplicativos digitais (como softwares de } \\
\text { simulação e de realidade virtual, entre outros) (BNCC, 2018, p. } \\
\text { 557). }\end{array}$ & \\
\hline $\begin{array}{l}\text { Identificar, analisar e discutir vulnerabilidades vinculadas às } \\
\text { vivências e aos desafios contemporâneos aos quais as juventudes } \\
\text { estão expostas, considerando os aspectos físico, psicoemocional e } \\
\text { social, a fim de desenvolver e divulgar ações de prevenção e de } \\
\text { promoção da saúde e do bem-estar (BNCC, 2018, p. 557). }\end{array}$ & \\
\hline
\end{tabular}

Fonte: Autores (2021). 
Com as situações-suporte, o professor emprega situações didáticas que auxiliam no processo de ensino e aprendizagem de modo que estas contribuam na promoção de competências e habilidades que se relacionam a tomadas de decisões na vida cotidiana desse aluno, as chamadas situações adidáticas (Brousseau, 2008). Característica essa demonstrada no seguinte trecho:

Aplicar os princípios da evolução biológica para analisar a história humana, considerando sua origem, diversificação, dispersão pelo planeta e diferentes formas de interação com a natureza, valorizando e respeitando a diversidade étnica e cultural humana (BNCC, 2018, p. 557).

A terceira Competência Específica concerne à resolução de problemas das diversas demandas sociais por meio da investigação de situações-problema.

Investigar situações-problema e avaliar aplicações do conhecimento científico e tecnológico e suas implicações no mundo, utilizando procedimentos e linguagens próprios das Ciências da Natureza, para propor soluções que considerem demandas locais, regionais e/ou globais, e comunicar suas descobertas e conclusões a públicos variados, em diversos contextos e por meio de diferentes mídias e tecnologias digitais de informação e comunicação (TDIC) (BNCC, 2018, p. 558).

As características das situações didáticas relacionadas as habilidades concernentes à terceira Competência Específica podem ser desenvolvidas por meio de situações didáticas que tenham por metodologia a resolução de problemas, pertencentes às situações-ação expressadas por Brousseau (2008), podendo ser percebidas na promoção de habilidades do seguinte trecho:

Construir questões, elaborar hipóteses, previsões e estimativas, empregar instrumentos de medição e representar e interpretar modelos explicativos, dados e/ou resultados experimentais para construir, avaliar e justificar conclusões no enfrentamento de situações-problema sob uma perspectiva científica. (BNCC, 2018, p. 559)

Hodson (1998) explicita que é preciso ter clareza a respeito da aplicação de metodologias investigativas, pois estas diferem da atividade realizada pelo cientista visto que a investigação com caráter pedagógico carrega consigo objetivos de aprendizagem já definidos. Freitas-Reis e Faria (2015) evidenciam em seu trabalho a necessidade de um ensino contextualizado de forma problemática que interligue diversos saberes para que os alunos possam ser preparados para as demandas sociais. No estudo de caso realizado pelos autores, os alunos passaram a relacionar o conteúdo químico ao seu cotidiano bem como desenvolveram habilidades importantes tais como identificar o problema, procurar e analisar as informações, levantar hipóteses e propor soluções. Habilidades estas bastante presente nas aplicações de situações-ação. Em consonância, Menezes e Farias (2020) relatam a promoção de tais habilidades em alunos do $2^{\circ}$ ano do Ensino Médio de uma escola do Município de Manaus por meio de uma atividade experimental investigativa que tinha como tema "conservação de alimentos pela diminuição da temperatura". Com isso, os alunos conseguiram argumentar de forma autônoma com base nos conceitos explorados.

No que concerne às situações como ferramenta pedagógica e às competências e habilidades específicas da BNCC, as características podem ser identificadas quando manipuladas por 4 possíveis meios: (1) utilização das Tecnologias de Informação e Comunicação, (2) metodologias investigativas, (3) abordagem sociocultural e (4) método de resolução de problemas.

Ao longo da aplicação de TICs através de abordagens socioculturais, pode-se haver promoção de competências e habilidades tais como: "identificar, analisar, modelar e solucionar problemas complexos em diversas áreas da vida cotidiana, explorando de forma efetiva o raciocínio lógico, o pensamento computacional, o espírito de investigação e a criatividade" (BNCC, 2018, p. 475). 
Desse modo, Pinheiro e Soares (2019) relatam a promoção de tais competências e habilidades do uso das TICs na produção de um jornal da Química como recurso didático de uma abordagem problematizadora. Por intermédio desse jornal confeccionado pode-se despertar o interesse do aluno bem como motivá-los de forma contextualizada e interdisciplinar durante o processo de ensino e aprendizagem, gerando por parte deles a apropriação das informações abordadas e uma visão mais crítica.

Brousseau (2008) apresenta a situação-contrato como a relação que cada parte envolvida na situação deverá gerir. Ainda que o autor desenvolva seus estudos no ensino de matemática, Souza, Simões Neto e Lima (2019) analisam essa perspectiva de situação-contrato no ensino de calorimetria por meio da Resolução de Situações-Problemas. A aplicação desses métodos investigativos e métodos de resoluções de problemas podem desenvolver as seguintes competências e habilidades:

“.... ampliar sua compreensão sobre a vida, o nosso planeta e o universo, bem como sua capacidade de refletir, argumentar, propor soluções e enfrentar desafios pessoais e coletivos, locais e globais.” (BNCC 2018, p. 472).

Competências e habilidades estas fomentadas em trabalhos como Anjos e Justi (2015), Freitas-Reis e Faria (2015) e Ferreira et al (2018) que ofertam abordagens, práticas e atividades de caráter investigativo com o intuito de motivar seus alunos a serem protagonistas no processo de ensino e aprendizagem assegurando o desenvolvimento de aprendizagens essenciais para as demandas sociais.

Ao avaliar as metodologias utilizadas em sala de aula dos professores de Ciência de uma cidade do Piaú, Soares et al (2021) relatam a dificuldade de implementação de metodologias ativas nas aulas de ciências dos professores entrevistados, tal fator se relaciona ao não conhecimento das metodologias ativas, a desmotivação dos docentes e aos aspectos estruturais das escolas. Com isso, foi expressa a necessidade de agregar as metodologias ativas na formação inicial dos professores bem como na formação continuada para que estes, a partir do contexto aos quais estão inseridos possam proporcionar situações didáticas de forma a promover o protagonismo estudantil por meio das metodologias ativas.

Mediante o desenvolvimento de práticas pedagógicas propostas pela BNCC como meio de uma situação didática, ao passo que estas são desenvolvidas, os alunos passam a construir estratégias para chegar a uma finalidade, convertendo-os em atuantes no processo de construção do seu conhecimento. Com a sucessão de tais situações-ação propostas ao longo do processo de ensino e aprendizagem, os alunos aprendem por meio do método de resolução de problemas e tornam-se reveladores das características pertinentes às situações (Brousseau, 2008).

\subsection{Tema: Situações didáticas como princípio curricular}

As características citadas por Brousseau (2008), no tocante ao protagonismo do estudante, quando desenvolvidas situações-ação que envolve situações de resolução de problemas podem ser explicitadas na BNCC por meio de outras práticas investigativas, podendo ser percebido no seguinte trecho:

.... a dimensão investigativa das Ciências da Natureza deve ser enfatizada no Ensino Médio, aproximando os estudantes dos procedimentos e instrumentos de investigação, tais como: identificar problemas, formular questões, identificar informações ou variáveis relevantes, propor e testar hipóteses, elaborar argumentos e explicações, ...., relatar, avaliar e comunicar conclusões e desenvolver ações de intervenção, a partir da análise de dados e informações sobre as temáticas da área (BNCC, 2018, p. 550).

Souza e Silva (2020) apontam a importância no processo formativo de envolver os alunos em situações com aspectos investigativos citados na BNCC, tais como observação, comunicação, escuta, escrita e reflexão sobre os contextos durante uma Sequência de Ensino Investigativa (SEI). Mediante contextualização do conteúdo químico a SEI possibilitou articular diversos saberes acerca da produção da rapadura assim como incentivou os estudantes a mobilizarem diversas habilidades de modo que 
estes se convertessem em protagonistas críticos e reflexivos em sua aprendizagem visto que puderam compreender que a ciência não se limita apenas a atividade laboratorial, uma vez que se faz presente em seu cotidiano.

Levando em consideração que a escolha de determinados meios que compõem as situações didáticas apresentados no documento promova o protagonismo estudante, Brousseau (2008) expressa que a tomada de consciência destes conhecimentos resulta na prática de certas interações sociais, bem como, em um sistema específico de saberes.

Tendo em vista tais aspectos discutidos, Tomaz et al (2019) abordam a aplicação de um Estudo de Caso (EC) em uma turma do noturno de uma escola da região Nordeste como alternativa de rompimento do ensino tradicionalista executado nas aulas de Química. Por meio deste EC os alunos conseguiram não somente refletir e se posicionar de forma crítica frente aos desafios impostos ao longo de sua aplicação, como também mobilizaram habilidades e saberes desenvolvidos através das atividades de caráter investigativo.

Foi possível observar na análise do documento que o termo "situação didática" não está presente de forma direta. Porém, verificamos sinalizações de indicativos das situações expressadas por Brousseau (2008). Estas, de forma geral, referem-se ao contexto que cerca o aluno no momento de sua aprendizagem, sendo incluídos neste o professor e o sistema educacional. Tais situações podem ser manipuladas a partir do meio que tem por encargo ser uma ferramenta de ensino empregada no ambiente de aprendizagem. Logo, por essa perspectiva, o professor deve selecionar determinadas práticas aproveitando-as ao máximo tendo em consideração a particularidade de cada uma delas a fim de provocar o aluno a ser um participante ativo na construção do seu conhecimento.

Considerando que essas práticas que compõem o meio em uma situação didática promovam o protagonismo do estudante, seus indicativos são tratados na BNCC como itens necessários para atender as diferentes demandas atendendo-se a heterogeneidade do aluno a fim de uma aprendizagem significativa, aspecto esse identificado nos seguintes trechos que diz respeitam as decisões tomadas no currículo a ser posto em ação: “.... selecionar e aplicar metodologias e estratégias didáticopedagógicas diversificadas, recorrendo a ritmos diferenciados e a conteúdos complementares, ...., para trabalhar com as necessidades de diferentes grupos de alunos ....”; “.... conceber e pôr em prática situações e procedimentos para motivar e engajar os alunos nas aprendizagens" (BNCC, 2018, p. 17)

Para Brousseau (2008), na perspectiva didática, é o comportamento do aluno que revela o funcionamento do meio possibilitando a modelação do mesmo para assegurar certo conhecimento. Portanto, o professor deve estar atento às demandas de suas classes para proporcionar uma interação de modo que fomente o protagonismo de seus estudantes intentando garantir aprendizagens essenciais por meio dessas ferramentas.

Brousseau (2008) manifesta a promoção deste protagonismo através de situações didáticas que tenham por metodologia a resolução de problemas, pois, a partir delas os alunos puderam atuar, refletir e evoluir de acordo com as adaptações realizadas pelos professores. Neste sentindo, o documento evidencia o valor da ação de metodologias que favoreçam e estimulem o protagonismo dos estudantes e propõe práticas que alcancem essa finalidade, citando a aprendizagem colaborativa, práticas investigativas e transdisciplinaridades.

Rezende et al (2019) descrevem a oportunidade de promover o protagonismo do estudante através da dinâmica do jogo educativo "RAIOQUIZ" utilizado para construção do conhecimento acerca do conceito de propriedades periódicas onde, ao longo de sua execução, foi possível constatar a motivação dos alunos a medida com que o nível de dificuldade aumentava bem como maior participação e interação entre os jogadores de maneira colaborativa. Dessa forma percebeu-se que com a utilização de tal metodologia houve favorecimento do protagonismo dos alunos tornando-os participantes ativos na construção de seu conhecimento. 
Com isso, ainda que a BNCC proponha abordagens e práticas que promovam o protagonismo estudantil, o professor é responsável pelo melhor caminho que promova aprendizagens efetivas a partir dos conteúdos essenciais, considerando as especificidades de seus alunos.

\section{Conclusão}

As interações entre o professor e o aluno no que concerne à mediação do conhecimento, construído ao longo do processo de ensino e aprendizagem, são essenciais na hora da escolha da situação didática que pode proporcionar o protagonismo do estudante, tendo em vista favorecer uma aprendizagem efetiva do conhecimento escolar.

Com o objetivo de identificar na BNCC indicativos de situações didáticas que favoreçam esse protagonismo do estudante, foi possível constatar no documento diversos elementos que compõem uma situação didática. Estes, sendo tratados de formas diversificadas levando em consideração os contextos aos quais os alunos estão envolvidos bem como o objetivo de proporcionar aos mesmos a oportunidade de se tornarem participantes ativos no processo de ensino e aprendizagem.

As características de situações didáticas identificadas no documento revelam a oportunidade de proporcionar ao aluno a promoção de competências e habilidades gerais e especificas de modo que estes passem a enfrentar as demandas sociais impostas em seu cotidiano, sendo essas denominadas por Brousseau (2008) como situações adidáticas, ou seja, a partir da mediação de situações didáticas, os alunos desenvolvem competências e habilidades que os tornam capazes de enfrentar de maneira não intencional as situações de seu cotidiano.

Mediante a utilização de instrumentos citados pelo documento tais como TICs, abordagens socioculturais, metodologias investigativas e de resolução de problemas pode-se proporcionar o protagonismo do estudante durante a execução da sequência didática a ser aplicada pelo professor como também promove o desenvolvimento de competências e habilidades necessárias para educação integral dos alunos da Educação Básica.

Ainda que o documento deixe a cargo do professor a escolha desses instrumentos, foi possível observar foco em fatores fundamentais que o professor deve levar em consideração para a formação básica de seus alunos, fatores estes que precisam estar focados no favorecimento do protagonismo estudante e na aprendizagem significativa para a formação de um cidadão crítico e consciente.

Com isso, espera-se que a presente pesquisa possa contribuir para futuros trabalhos acerca do tema bem como auxiliar os docentes que atuam na educação básica no que concerne promover aos alunos situações didáticas que favoreçam seu aprendizado de maneira ativa tornando-os protagonistas na construção de seus conhecimentos.

\section{Referências}

Anjos, M. M. O., Justi, R. (2015). Favorecendo a discussão de alguns aspectos de natureza da ciência no ensino médio. Química Nova na Escola, 37 (Especial 1). $10.5935 / 0104-8899.20150013$

Bardin, L. (2009). Análise de Conteúdo. Tradução de Luís A. Reto e Augusto Pinheiro (5a ed). Edições 70.

Bogdan, R., \& Biklen, S. K. (2013). Investigação Qualitativa em Educação. Porto Editora.

Brasil. Ministério da Educação. Secretaria da Educação Básica. (2018). Base Nacional Comum Curricular: Ensino Médio.

Brousseau, G. (2008). Introdução ao estudo das situações didáticas: conteúdos e métodos. Ática.

Delors, J. et al. (1998). Educação: um tesouro a descobrir: relatório para a UNESCO da Comissão Internacional sobre Educação para o Século XXI. Cortez., UNESCO.

Dionízio, T. P. et al. (2019) O uso de Tecnologias da Informação e Comunicação como Ferramenta Educacional Aliada ao Ensino de Química. EaD em Foco, 9(1). 10.18264/eadf.v9i1.809

Ferreira, W. M et al. (2018). Corantes: uma abordagem com enfoque Ciências, Tecnologia e Sociedade (CTS) usando processos oxidativos avançados. Química Nova na Escola, 40(4). 10.21577/0104-8899.20160118 
Freire, P. (2019). Pedagogia da autonomia (68a Ed). Paz e Terra.

Lima, D. B. (2012). O Ensino Investigativo e suas Contribuições para a Aprendizagem de Genética no Ensino Médio (Trabalho de Conclusão de Curso). Universidade Federal do Rio Grande do Sul, Porto Alegre, Rio Grande do Sul, Brasil.

Lüdke, M., \& Andre, M. E. D. A. (2013). A Pesquisa em educação: abordagens qualitativas (2a ed). E.P.U.

Freitas-Reis, I., \& Faria, F. L. (2015). Abordando o tema alimentos embutidos por meio de uma estratégia de ensino baseada na resolução de casos: os aditivos alimentares em foco. Química Nova na Escola, 37(1). 10.21577/0104-8899.20160118

Menezes, J. M. S., \& Farias, S. A. (2020). O desenvolvimento de argumentação e mobilização de conceitos químicos por meio da atividade experimental investigação. Revista Virtual de Química, 12(1), 223-233. 10.21577/1984-6835.20200017

Moreira, H., \& Caleffe, L. G. (2008). Metodologia da Pesquisa para o Professor Pesquisador (2a ed). Lamparina.

Pinheiro, R. S. G., \& Soares, M. H. F. B. (2019). O jornal da química como etapa inicial de abordagem problematizadora: proposta para ensino e formação de professores. Química Nova na Escola, São Paulo, v. 41(2). 10.21577/0104-8899.20160134

Pozo, J. I. (2002). Aprendizes e Mestres A nova cultura da aprendizagem. Artmed.

Protagonismo. (2021). In: DICIO, Dicionário Online de Português. Matosinhos: 7Graus. https://www.dicio.com.br/protagonismo

Resolução $C N E / C P n^{o}$ 2, de 20 de dezembro de 2019. Define as Diretrizes Curriculares Nacionais para a Formação Inicial de Professores para a Educação Básica e institui a Base Nacional Comum para a Formação Inicial de Professores da Educação Básica (BNC-Formação).

Rezende, F. A. M et al. (2019). RAIOQUIZ: Discussão de um Conceito de Propriedade Periódica por Meio de um Jogo Educativo. Química Nova na Escola, 41(3). 10.21577/0104-8899.20160134

Roegiers, X. (2006) Aprendizagem integrada: situações do cotidiano escolar. Tradução Jeni Wolff. Artmed.

Santos, S. C. M., Souza, J. R., \& Fontes, A. L. L. (2020). Protagonismo estudantil em feira de ciências na escola. Educação \& Formação, 5(3). redufor.v5i15set/dez.2151

Silva, V. A., \& Soares, M. H. F. B. (2018). O uso das tecnologias de informação e comunicação no ensino de Química e os aspectos semióticos envolvidos na interpretação de informações acessadas via web. Ciência \& Educação, 24(3), 639-657. 10.1590/1516-73132018003007

Soares, M. S. et al. (2021). O uso de metodologias ativas de ensino por professores de Ciências nas escolas de Angical - PI. Research, Society and Development, 10(13). 10.33448/rsd-v10i13.21220

Souza, A. A. M., Silva, F. C. V. (2020). Uma proposta de Sequência de Ensino Investigativa para articulação de diferentes saberes sobre a produção da rapadura. In: Encontro Nacional De Ensino De Química, Pernambuco, Brasil, 20.

Souza, L. O., Simões Neto, J. E., \& Lima, A. P. A. B. (2019). A dinâmica do contrato didático no ensino de calorimetria por resolução de situações-problema: a simultaneidade de duas relações contratuais. Química Nova na Escola, 41(1). 10.21577/0104-8899.20160140

Teixeira, A. L. S., Araújo, K. C. C., Bernardino, R. M., \& Schulz, L. (2015). A importância do trabalho investigativo no cotidiano escolar do ensino de Ciências. In: Congresso Nacional Da Educação Conedu, Campina Grande, Paraíba, Brasil, 2.

Tomaz, A. R et al. (2019). O método de estudo de caso como alternativa para o ensino médio noturno. Química Nova na Escola, 41(2). 10.21577/01048899.20160158

Vilanova, R. (2015). Educação em ciências e cidadania: mudança discursiva e modos de regulação na política do Programa Nacional do Livro Didático. Ciência \& Educação, 21(1), 177-197. 10.1590/1516-731320150010012

Volkweiss, A et al. (2019). Protagonismo e participação do estudante: desafios e possibilidades. Educação por escrito, 10(1). 10.15448/21798435.2019.1.29112

Zômpero, A. F., \& Laburú, C. E. (2011). Atividades investigativas no ensino de ciências: aspectos históricos e diferentes abordagens. Revista Ensaio, 13(3), 67-80. https://www.scielo.br/j/epec/a/LQnxWqSrmzNsrRzHh3KJYbQ/?lang=pt\&format=pdf 